\title{
BMJ Open Impact of workplace incivility in hospitals on the work ability, career expectations and job performance of Chinese nurses: a cross-sectional survey
}

Shu'e Zhang, ${ }^{1}$ Chongyi Ma, ${ }^{2}$ Dexin Meng, ${ }^{3}$ Yu Shi, ${ }_{1}^{1}$ Fengzhe Xie, ${ }^{1}$ Jinghui Wang, ${ }^{1}$ Xinpeng Dong, ${ }^{4}$ Jiao Liu, ${ }^{5}$ Shuang Cang, ${ }^{6}$ Tao Sun ${ }^{1}$

To cite: Zhang S, Ma C, Meng D, et al. Impact of workplace incivility in hospitals on the work ability, career expectations and job performance of Chinese nurses: a crosssectional survey. BMJ Open 2018;8:e21874. doi:10.1136/ bmjopen-2018-021874

\section{- Prepublication history for} this paper is available online. To view these files, please visit the journal online (http://dx.doi org/10.1136/bmjopen-2018021874).

S'Z and CM contributed equally.

Received 1 February 2018 Revised 24 July 2018

Accepted 11 October 2018
Check for updates

(C) Author(s) (or their employer(s)) 2018. Re-use permitted under CC BY-NC. No commercial re-use. See rights and permissions. Published by BMJ.

For numbered affiliations see end of article.

Correspondence to Professor Tao Sun; hydsunta0@126.com

\section{ABSTRACT}

Objectives The objectives of this study were to investigate new nurses' experiences of workplace incivility; verify the mediating role of work ability in the relationship between workplace incivility and job performance and examine the moderating role of career expectations in the relationship between workplace incivility and job performance.

Design This cross-sectional survey was conducted in China in May 2016.

Settings The research settings included 54 cities across 29 provinces of China.

Participants Of the 903 participants recruited, 696 new nurses ( $<3$ years of nursing experience) agreed to complete the online questionnaire of the study. The effective response rate was $77.1 \%$. The inclusion criteria were voluntary participation, $<3$ years of nursing experience and recognition as a registered nurse. The exclusion criteria were refusal to participate, $>3$ years of nursing experience or not recognised as a registered nurse.

Results New nurses (60.7\%) experienced some level of workplace incivility in the previous year, and it was more frequent among those with higher educational degrees. Work ability mediated the relationship between workplace incivility and job performance, and this relationship was moderated by career expectations.

Conclusion Incivility towards new nurses was relatively common in the workplace. Workplace incivility impairs job performance by weakening the work ability of new nurses. Higher career expectations may buffer workplace incivility and contribute to the maintenance of job performance by buffering the detrimental effects of workplace incivility.

\section{INTRODUCTION}

Andersson and Pearson defined workplace incivility as 'low intensity deviant behaviour with ambiguous intent to harm the target, in violation of workplace norms for mutual respect'. ' Workplace incivility is described as rude, discourteous, belittling and insulting behaviour. It is pervasive in healthcare settings and can permeate an entire work environment. $^{2}$ It may have a destructive
Strengths and limitations of this study

- This is the first study to investigate the relationship between workplace incivility and job performance among new nurses in China.

- Research with this sample from China should add to the global understanding of workplace incivilitythat it occurs in different cultures and healthcare systems.

- This innovative study examined the moderating role of career expectations on the relationship between workplace incivility and job performance.

- The data were obtained using self-reports of new nurses, which, to some extent, resulted in response bias (social desirability).

- Samples from the different regions of China were not proportional.

influence on the sustainable development of medical and healthcare organisations. ${ }^{3}$ Unfortunately, workplace incivility negatively effects employees' mental health and emotional well-being, often causing symptoms of anxiety, depression, somatic symptoms, fatigue and illnesses among nurses. ${ }^{4-6}$ These negative emotions and physical consequences can hamper nurses' development of their work abilities. Furthermore, the spread of negative emotions is likely to have adverse effects on nurses' work environments. ${ }^{3}$ Workplace incivility has a long cycle and adverse effects on new nurses. High career expectations are accompanied by high motivation, which promotes positive behaviours that may buffer negative emotional experiences caused by workplace incivility. An investigation of current workplace incivility, its mechanisms and negative effects is important, especially in relation to the work ability, career expectations and job performance of new nurses. 


\section{Incivility in the workplace}

Workplace incivility is prevalent worldwide, and its damaging effects on the development of individuals and organisations have been documented. ${ }^{6}$ At the individual level, workplace incivility can decrease workers' job involvement and impair their job performance. It may also reduce or eliminate employees' job satisfaction and organisational loyalty, and increase their turnover rates. ${ }^{7}$ Victims of workplace incivility suffer from depression, mood swings and other negative emotions, which seriously compromise their mental and physical health. ${ }^{8}$ At the organisational level, victims tend to be isolated from surrounding social networks. Victims, witnesses and stakeholders involved in workplace incivility may react to it with behaviours that undermine organisational resources and threaten organisational development. ${ }^{7}$ More importantly, workplace incivility can spread to the social level, which may escalate to more aggressive behaviour and evoke workplace violence. ${ }^{9}$ Nursing in China, a predominantly female profession, ${ }^{10}$ primarily involves clinical work under stressful conditions of staff shortages. ${ }^{10}$ Workplace incivility hampers professional nursing practice, and decreases the quality of patient care and the health of the nurses. ${ }^{11}$ The nursing profession has been associated with the phrase 'nurses eat their young', which is viewed by many an initiation rite to determine whether a new nurse can survive their profession. Workplace incivility can have a substantial negative impact on new nurses. ${ }^{12}$ Not surprisingly, new nurses can barely distinguish between the theoretical orientation of their nursing education and the focus of clinical practice. Most new nurses lack key competencies, including nursing skills, to respond appropriately to emergencies or effectively manage issues related to the nurse-patient relationship. ${ }^{13}$ New nurses who lack work skills and competencies, ${ }^{14}$ frequently experience workplace mistreatment. ${ }^{1415}$ increasing their vulnerability to incivility. ${ }^{16}$ Workplace incivility is a subtle form of workplace mistreatment with devastating effects (eg, mental health) on new nurses. ${ }^{17}$ There are numerous anecdotal reports about the effects of incivility in nursing and healthcare settings (eg, burnout, high turnover rates and job dissatisfaction). ${ }^{18} 19$ However, no empirical research has examined this problem among new nurses in China.

\section{Impact of workplace incivility on work ability, career expectations and job performance}

The work ability of new nurses is influenced by their work environment, work organisation and workload. Creating a work environment and providing humanistic care is necessary for their development. ${ }^{20}$ Work ability is defined as workers' abilities to perform their jobs, taking into account specific work demands and individuals' health and mental resources. ${ }^{21}$ Previous studies have found a link between work ability and various work-related factors, including mental demands, professional development opportunities, satisfaction with work schedule, manager's style and satisfaction with work prospects and salary. ${ }^{21} 22$ New nurses are expected to adapt to their new roles quickly and smoothly, although their technological skills, clinical experience and adaptability to the work environment are limited. ${ }^{22}$ New nurses are the principal victims of nursing incivility. Previous studies showed a significant association between violence at work and reduced working ability, ${ }^{23}$ which is a manifestation of job performance, and might be closely related to workplace incivility and job performance. These correlations clarify their influence on new nurses.

Career expectations can be categorised as an individual's inclination and an externalisation of professional values, which manifests as a person's philosophy and values. It is one of the most basic and important psychological functions, ${ }^{24}$ which encourages employees to achieve their desired goals, such as salary, welfare, work environment and conditions and development opportunities. Traditional expectancy-value theory posits that job performance is influenced by the assessment of individual behaviours and expectations related to the results. That is to say, new nurses with higher career expectations tend to exhibit higher levels of persistence in the process of achieving their goals; thus, promoting positive results. In contrast, nurses with low career aspirations show decreased motivation, leading to lower aspirations and persistence, and, subsequently, fewer contributions to the organisation. ${ }^{25}$ New nurses have career expectations based on a desire or passion for nursing, powered by an internal decision to make nursing a career, which can alleviate negative emotions caused by incivility. Occupational expectations have intrinsic power to promote engagement in the nursing profession, which is a determinant of performance. ${ }^{25}$ Therefore, it is imperative to explore how career expectations influence the job performance of new nurses after they have experienced incivility.

Workplace incivility is very damaging to organisations. It causes reduced job performance of employees and fosters their intentions to leave the job. ${ }^{18}$ Job performance is defined by Motowidlo (2003) as a value of work by an employee, which is expected by an organisation over a period. In the healthcare settings, nurses' job performance is tied to increases in health outcomes, and to behaviour processes, both of which concern patient satisfaction and quality of life. ${ }^{18}$ However, goals and the motivation to achieve them are determinants of job performance. Previous studies showed that incivility experienced by nurses negatively affects their psychological state, job performance and well-being. ${ }^{26}$ Scholars have confirmed that incivility is negatively related to job performance and that the association is fully mediated by emotional exhaustion. ${ }^{26}$ Therefore, improving the job performance of new nurses from the perspective of work ability and expectations deserves attention. Further investigation of this harmful workplace phenomenon and encouragement of practitioners to develop policies and procedures to reduce its occurrence are warranted.

This study aimed first, to evaluate the current state of workplace incivility, as experienced by new Chinese nurses 


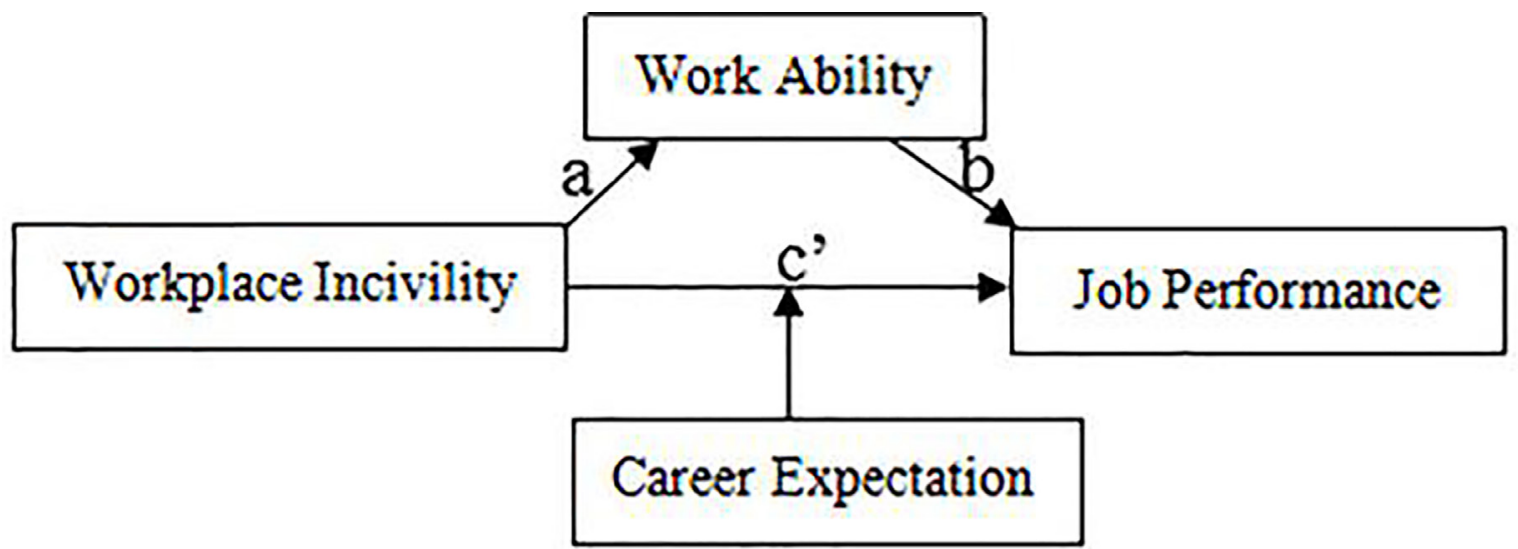

Figure 1 Conceptual framework of the study.

and examine the association between workplace incivility and job performance. Second, it examined the mediating role of work ability on the relationship between incivility and job performance. Third, it explored the moderating role of career expectations on the relationship between incivility and job performance, as shown in figure 1 .

\section{METHODS}

\section{Participants and procedures}

Snowball sampling was used to collect data. Nurses throughout China completed an anonymous online questionnaire in May 2016. This cross-sectional study was conducted across 29 provinces in China. Approximately 60 nurses (with $<3$ years of service) from the authors' units were selected to be the 'original deliverers' of the survey. The original deliverers were alumni who maintained friendly contact with the researchers and had nursing positions in various hospitals. Prior to commencement of the formal online survey, we provided comprehensive survey training to these initial contacts, and commissioned them to recruit 10-20 nurses to answer the questionnaire during the same period. A web page link to our questionnaire (https://www.wenjuan.com/) was sent by mobile phone to participants during their rest breaks. The amount of data collected was monitored in real time on the website's management platform. There were no 'required responses' in the online questionnaire. Our sample was selected with strict adherence to exclusion criteria for data management and quality control. For example, we eliminated unanswered or incomplete questionnaires and those answered in an extremely short period and/or with an excessive amount of blank items.

Participants were recruited for the study from 29 cities in China; 903 participants were enrolled and data from 696 valid questionnaires were analysed. The effective response rate was $77.1 \%$. The inclusion criteria were recognition as a registered nurse, $<3$ years of nursing experience and voluntary participation in the study. The exclusion criteria were not recognised as a registered nurse, $>3$ years of nursing experience and refusal to participate in the study.
Patient and public involvement statement

There was no patient or public participation in this study.

\section{Ethical considerations}

As the survey was anonymous, it was impossible to obtain written informed consent. Therefore, an informed consent form was included on the cover of the questionnaire. The completed questionnaire was considered informed consent to participate in the survey. Confidentiality was maintained for all information collected in the survey.

\section{Measures and tools}

Demographic variables included gender, age, work experience, marital status, professional position and educational level.

\section{Experience of incivility}

A widely used 12-item measure developed by Cortina et al was used in this study to assess new nurses' experiences of workplace incivility. ${ }^{27}$ They were instructed to rate the frequency of the experience presented in each item. A sample item was: "During the past year, how many times have you been in a situation where a coworker or supervisor paid little attention to your statements or showed little interest in your opinions"? Responses were scored on a 5-point scale from 1 (never) to 5 (very frequently). We averaged the responses of the 12 items, with a high score reflecting a high level of workplace incivility. The validity and reliability of the scale have been examined in workplaces with Chinese nurses. ${ }^{28}$ Cronbach's $\alpha$ coefficient for the scale was 0.893 .

\section{Work ability index}

A single question from the work ability index (WAI) ${ }^{29}$ was used to assess work ability, specifically the nurses' ratings of their 'current work ability compared with their lifetime best'. The total possible score ranged from 0 (completely unable to work) to 10 (work ability at its best), and a high score indicated a high level of work ability. The WAI is a widely used valid and reliable measure of work ability. ${ }^{21}$ 


\section{Career expectations}

A single question was adopted from the WAI to measure the new nurses' career expectations, specifically, their 'current career expectations compared with their lifetime best'. The total possible score ranged from 0 (no career expectations) to 5 (high career expectations). A high score indicated high career expectations. Previous literature has suggested that a single-item questionnaire with high validity and sensitivity can measure these expectations of new nurses. ${ }^{30}$

\section{Job performance}

Job performance was assessed using the Job Performance Scale developed by Williams and Andersons, ${ }^{31}$ which included five items. We used a 5-point Likert scale ranging from 1 (strongly disagree) to 5 (strongly agree), with a high score indicating a high level of job performance. Cronbach's $\alpha$ for the scale was 0.934 .

\section{Data analysis}

All data were analysed using SPSS Statistical Software for Windows V.17.0 (SPSS, Chicago, Illinois, USA). Hierarchical linear regression was performed to test the relationships between the variables and the mediating and moderating effects. Statistical significance was set to $\mathrm{p}<0.05$ (two-tailed).

\section{RESULTS \\ Descriptive statistics}

Participants' demographic data are summarised in table 1 . The mean age of the new nurses was 24.55 years (19-25). Female nurses comprised $90 \%$ of the sample, and $97.6 \%$ of them had at least a college education; $85.34 \%$ were unmarried and $83.3 \%$ were from tertiary hospitals. They worked in different hospital departments and had $<3$ years of nursing experience. Analyses revealed that $60.7 \%(\mathrm{n}=696)$ of the new nurses had experienced some level of workplace incivility during the past year (table 2). Differences in workplace incivility scores across educational levels was statistically significant $(\mathrm{F}=6.442$, $\mathrm{p}<0.01$ ) (table 1).

\section{Correlations between the study variables}

The means, SD and Pearson's correlation coefficients of the continuous variables are presented in table 3 . All the variables were significantly correlated with one another, and workplace incivility was negatively correlated with work ability $(\mathrm{r}=-0.403, \mathrm{p}<0.01)$, career expectations $(\mathrm{r}=-0.298, \mathrm{p}<0.01)$ and job performance $(\mathrm{r}=-0.202$, $\mathrm{p}<0.01$ ). Work ability was positively correlated with career expectations $(\mathrm{r}=0.366, \mathrm{p}<0.01)$ and job performance $(\mathrm{r}=0.351, \mathrm{p}<0.01)$. There also was a positive correlation between the career expectations and job performance $(\mathrm{r}=0.389, \mathrm{p}<0.01)$. The absolute value of the correlation coefficient was between 0.25 and 0.63 , which indicated that each variable could be used in the subsequent regression analyses.
Table 1 Characteristics of the respondents $(n=696)$

\begin{tabular}{|c|c|c|c|c|}
\hline \multirow[b]{2}{*}{ Characteristic } & \multirow[b]{2}{*}{$\mathbf{N}$} & \multirow[b]{2}{*}{$\%$} & \multicolumn{2}{|c|}{ Workplace incivility } \\
\hline & & & $\mathbf{F}$ & $P$ value \\
\hline Gender & & & 0.549 & 0.459 \\
\hline Male & 67 & 9.60 & & \\
\hline Female & 629 & 90.40 & & \\
\hline Marital status & & & 3.639 & 0.027 \\
\hline Unmarried & 594 & 85.34 & & \\
\hline Married & 99 & 16.67 & & \\
\hline Divorced or widowed & 3 & 0.04 & & \\
\hline Hospital level & & & 2.784 & 0.062 \\
\hline Tertiary hospital & 580 & 83.30 & & \\
\hline Secondary hospital & 90 & 12.90 & & \\
\hline Primary hospital & 26 & 3.70 & & \\
\hline \multicolumn{5}{|l|}{ Education level } \\
\hline Secondary or below & 17 & 8.10 & 6.442 & 0.002 \\
\hline Associate degree & 253 & 31.60 & & \\
\hline Bachelor or above & 426 & 57.60 & & \\
\hline \multicolumn{5}{|l|}{ Service years } \\
\hline$<0.5$ & 43 & 6.20 & 0.727 & 0.603 \\
\hline $0.5-0.9$ & 314 & 45.10 & & \\
\hline $1-1.4$ & 69 & 9.90 & & \\
\hline $1.5-1.9$ & 112 & 16.10 & & \\
\hline $2-2.4$ & 73 & 10.50 & & \\
\hline$>2.5$ & 85 & 12.20 & & \\
\hline \multicolumn{5}{|l|}{ Departments } \\
\hline Job rotation & 102 & $14.60 \%$ & 1.201 & 0.291 \\
\hline Medical department & 165 & $23.70 \%$ & & \\
\hline Surgery department & 178 & $25.60 \%$ & & \\
\hline Medical technical department & 25 & $3.60 \%$ & & \\
\hline Outpatient department & 30 & $4.30 \%$ & & \\
\hline Gynaecology department & 41 & $5.90 \%$ & & \\
\hline Paediatrics department & 29 & $4.20 \%$ & & \\
\hline Others & 126 & $18.10 \%$ & & \\
\hline
\end{tabular}

\section{Hierarchical linear regression models}

Several multivariate hierarchical linear regression analyses were performed to examine the association of workplace incivility with the job performance, work ability and career expectations of the new nurses (table 4). To examine these relationships, we conducted three mediation analyses using linear regression methods described by Baron and Kenny. ${ }^{32}$ Workplace incivility was analysed as a predictor variable in the models, work ability as a mediating variable and job performance as an independent variable. Career expectations was analysed as a moderating variable in these models. Age, gender, hospital level, years of experience, educational level and hospital department were used as control variables $\left(M_{1}, M_{3}\right)$ to eliminate the effects of demographic and work variables on the regression models (table 4).

The regression models showed workplace incivility had a significant negative association with the work ability $\left(\beta=-0.388, \mathrm{p}<0.01, M_{2}\right)$ and the job performance $\left(\beta=-0.199, p<0.01, M_{5}\right)$ of new nurses after controlling 
Table 2 Incidence states of workplace incivility among new nurses $(n=696)$

\begin{tabular}{|c|c|c|c|c|c|}
\hline $\begin{array}{l}\text { Workplace incivility item } \\
(\mathrm{n}=696)\end{array}$ & $\begin{array}{l}\text { Never } \\
\mathrm{N}(\%)\end{array}$ & $\begin{array}{l}\text { Occasionally } \\
\text { N (\%) }\end{array}$ & $\begin{array}{l}\text { Sometimes } \\
\mathbf{N}(\%)\end{array}$ & $\begin{array}{l}\text { Frequently } \\
\mathrm{N}(\%)\end{array}$ & $\begin{array}{l}\text { Very } \\
\text { frequently } \\
\mathrm{N}(\%)\end{array}$ \\
\hline $\begin{array}{l}\text { Paid little attention to your statements or showed little interest in } \\
\text { your opinions }\end{array}$ & $77(11.1 \%)$ & $217(31.2 \%)$ & $322(46.3 \%)$ & $72(10.3 \%)$ & $8(1.1 \%)$ \\
\hline $\begin{array}{l}\text { Doubted your judgement on a matter over which you had } \\
\text { responsibility }\end{array}$ & $64(9.2 \%)$ & $267(38.4 \%)$ & $299(43 \%)$ & $60(8.6 \%)$ & $6(1.9 \%)$ \\
\hline Gave you hostile looks, stares or sneers & $356(5.1 \%)$ & $252(36.2 \%)$ & $80(11.5 \%)$ & $7(1 \%)$ & $1(0.1 \%)$ \\
\hline Interrupted or 'spoke over' you & $149(21.4 \%)$ & $319(45.8 \%)$ & $184(26.4 \%)$ & $41(5.9 \%)$ & $3(0.4 \%)$ \\
\hline Rated you lower than you deserved on an evaluation & $171(24.6 \%)$ & $314(45.1 \%)$ & $181(26 \%)$ & $27(3.9 \%)$ & $3(0.4 \%)$ \\
\hline Yelled, shouted or swore at you & $364(52.3 \%)$ & $225(32.3 \%)$ & $85(12.2 \%)$ & $17(2.4 \%)$ & $5(0.7 \%)$ \\
\hline Made insulting or disrespectful remarks about you & $503(72.3 \%)$ & $156(22.4 \%)$ & $33(4.7 \%)$ & $4(0.6 \%)$ & $0(0.00 \%)$ \\
\hline Ignored you or failed to speak to you & $361(51.9 \%)$ & $243(34.1 \%)$ & $77(11.1 \%)$ & $12(1.7 \%)$ & $3(0.4 \%)$ \\
\hline
\end{tabular}

for the demographic and work variables; work ability had a significant positive association with job performance $\left(\beta=0.338, p<0.01, M_{4}\right)$. When the mediation variable (work ability) was controlled for, the regression coefficient $(\beta=-0.080)$ decreased from the coefficient in the previous model $(\beta=-0.199)$, and was no longer statistically significant. Therefore, work ability $\left(\beta=0.305, \mathrm{p}<0.01, M_{6}\right)$ had a full mediating effect (figure 2).

In the last two models, career expectations had a positive association with job performance $(\beta=0.360, \mathrm{p}<0.01$, $\left.M_{7}\right)$. The interaction term between workplace incivility and career expectations was significant $(\beta=-0.568$, $\left.\mathrm{p}<0.01, M_{8}\right)$, and career expectations had a moderating effect on the relationship between workplace incivility and job performance. The moderating effect was estimated by referencing a previous study. ${ }^{33} 34$ This interaction effect is illustrated in figure 2. A simple slope test revealed that both high and low career expectations were correlated with the nurses' performance in workplaces with high levels of incivility. Job performance was significantly better among new nurses with high career expectations than those with low expectations (figure 3).

\section{DISCUSSION}

In this study, $60.7 \%$ of new nurses reported experiencing some level of workplace incivility in the past year. This result is consistent with the finding that $27 \%-85 \%$ of nurses experience incivility ${ }^{33}$ and might be due to the particular status of the nursing profession in the current medical environment and the structure of medical resources of China. China is a collectivistic and unequal society, in which 'Jun Chen' thought and caste-consciousness are deeply rooted. New nurses are accustomed to obeying the rules of their leaders and colleagues; hence, the unfavourable workplace. However, internal mechanisms remain to be tested in future research. This study investigated the incidence of workplace incivility among new nurses and found they reported a high incidence of rude behaviour during the past year.

The nurses with high educational degrees pursue autonomy, innovation, individuality and diversity. Work allocation is not clear in the nursing profession; so, they feel undervalued because of the repetitive nature of the work, ${ }^{34}$ which contributes to the development of role conflict. ${ }^{34}$ Nurses with higher educational degrees experience a gap between the ideal and the real workplace when facing difficulties, and struggle to adapt to the new environment and organisational culture. Ultimately, incompetent performance leads to admonition and workplace incivility.

The findings of this study are consistent with previous research finding. ${ }^{18} 35$ Workplace incivility had a significant negative association with new nurses' work ability $(\beta=-0.388, \mathrm{p}<0.01)$ and job performance $(\beta=-0.199$,

Table 3 Means, SD and correlations of continuous variables $(n=696)$

\begin{tabular}{|c|c|c|c|c|c|c|}
\hline Variables & Mean & SD & 1 & 2 & 3 & 4 \\
\hline 2. Work ability & 6.610 & 2.133 & $-0.403^{\star *}$ & 1 & & \\
\hline 4. Job performance & 3.204 & 0.885 & $-0.202^{\star \star}$ & $0.351^{\star *}$ & $0.389^{\star *}$ & 1 \\
\hline
\end{tabular}

${ }^{* *} \mathrm{P}<0.01$, correlation is significant at the 0.01 level (two-tailed). 
Table 4 Hierarchical linear regression models of mediation and moderation $(n=696)$

\begin{tabular}{|c|c|c|c|c|c|c|c|c|}
\hline \multirow[b]{2}{*}{ Variables } & \multicolumn{2}{|c|}{ Work ability } & \multicolumn{6}{|c|}{ Job performance } \\
\hline & $\begin{array}{l}M_{1} \\
\text { (step 1) }\end{array}$ & $\begin{array}{l}M_{2} \\
\text { (step 1) }\end{array}$ & $\begin{array}{l}M_{3} \\
\text { (step 2) }\end{array}$ & $\begin{array}{l}M_{4} \\
\text { (step 2) }\end{array}$ & $\begin{array}{l}M_{5} \\
\text { (step 2) }\end{array}$ & $\begin{array}{l}M_{6} \\
\text { (step 3) }\end{array}$ & $\begin{array}{l}M_{7} \\
\text { (step 4) }\end{array}$ & $\begin{array}{l}M_{8} \\
\text { (step 4) }\end{array}$ \\
\hline Workplace incivility & & $-0.388^{\star *}$ & & & $-0.199^{\star \star}$ & $-0.080^{*}$ & $-0.090^{\star}$ & $0.369^{\star \star}$ \\
\hline \multicolumn{9}{|l|}{ Mediating variable } \\
\hline Career expectation & & & & & & & $0.360^{\star *}$ & $0.830^{\star *}$ \\
\hline $\begin{array}{l}\text { Career expectation- } \\
\text { interaction }\end{array}$ & & & & & & & & $-0.568^{\star \star}$ \\
\hline $\mathrm{F}$ & $6.009^{\star \star}$ & $24.145^{\star \star}$ & $3.128^{\star \star}$ & $15.311^{\star \star}$ & $6.856^{\star \star}$ & $13.993^{\star \star}$ & $19.063^{\star \star}$ & $19.154^{\star \star}$ \\
\hline
\end{tabular}

${ }^{*} \mathrm{P}<0.05 ;{ }^{* *} \mathrm{P}<0.01$

$M_{1}$ : explains the influence of demographic variables on work ability (step 1).

$M_{2}$ : explains the influence of workplace incivility on work ability (step 1).

$M_{3}$ : explains the influence of demographic variables on job performance (step 2).

$M_{4}$ : explains the influence of work ability on job performance (step 2).

$M_{5}$ : explains the influence of workplace incivility on job performance (step 2).

$M_{6}$ : explains the influence of workplace incivility on job performance after bringing into the explanatory power of work ability (step 3).

$M_{7}$ : explains the influence of workplace incivility on job performance after bringing into the explanatory power of career expectation (step 4).

$M_{8}$ : explains the influence of workplace incivility on job performance after bringing into the explanatory power of career expectation and career expectation-interaction (step 4).

$\mathrm{p}<0.01)$. This study also makes a new theoretical contribution, in that workplace incivility had both direct and indirect effects on new nurses' performance and work ability $(\beta=0.305, p<0.01)$, and fully mediated this relationship. Career expectations $(\beta=-0.568, \mathrm{p}<0.01)$ had a moderating role. Ultimately, workplace incivility may reduce job performance by weakening the work ability of new nurses; however, high career expectations may buffer the negative emotional effects of workplace incivility and improve performance by altering the direction of the relationship. Possible mechanisms are described below.

Past studies have shown that individuals' emotional responses to workplace events largely determine their attitudes and subsequent behaviours. ${ }^{36}$ As a novice in the workplace with unique professional characteristics, new nurses are an easy target for workplace incivility from supervisors and colleagues. Those who experience negative events are more likely to develop

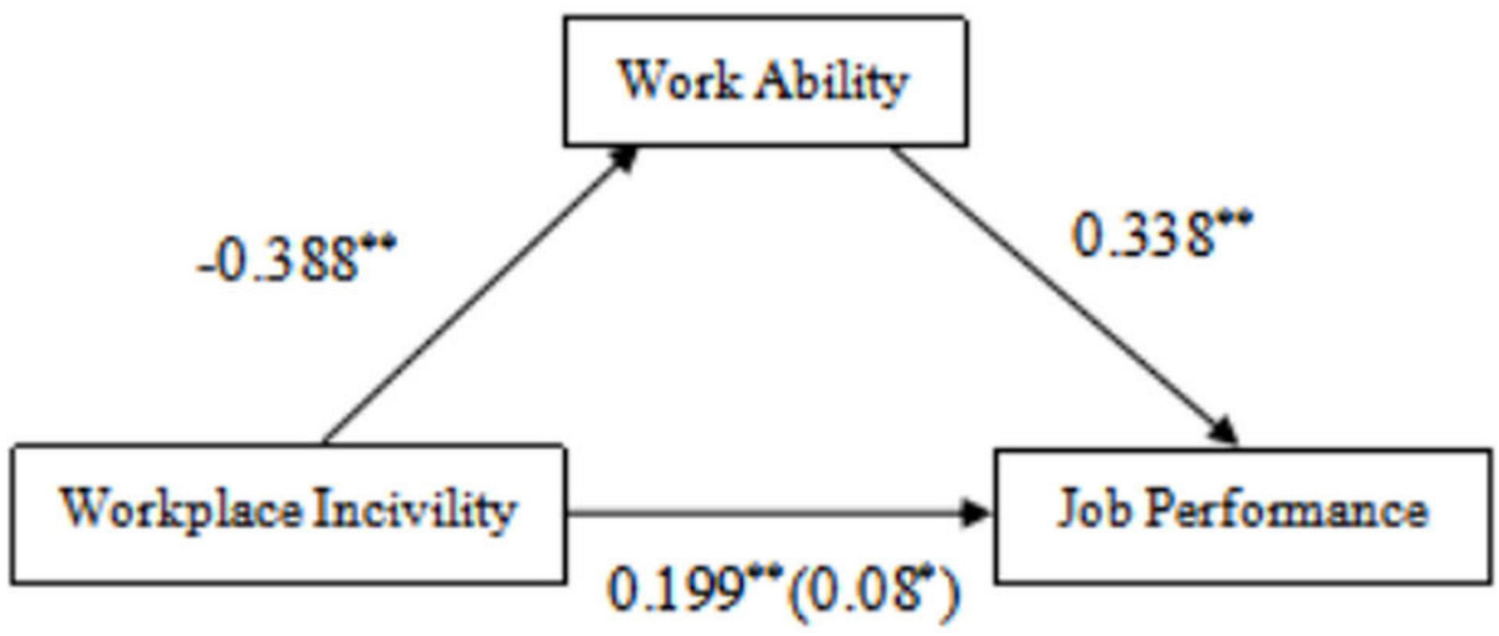

Figure 2 Standardised regression coefficients for the relationship between workplace incivility and job performance as mediated work ability. Standardised regression coefficients for the relationship between workplace incivility and job performance as mediated work ability, controlling for work ability, is in parentheses. 
4.5

4

3.5

3

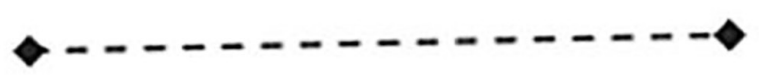

2.5

\section{low workplace incivility}

\section{high workplace incivility}

\section{$\diamond-\diamond$ low career expectation $\prec$ high car eer expectation}

Figure 3 Graphical representation of the interaction between workplace incivility and career expectation predicting job performance interference.

negative emotions and behaviours. ${ }^{36}$ Nurse's work ability encompasses their performance across the nursing process, and it is related to their clinical experiences, psychological states and motivation. ${ }^{37}$ New nurses may feel stressed when facing a gap between higher career expectations and lower clinical competence, and when they experience ambiguous and subtle behaviours, such as ignoring their reasonable requests, being treated unfairly, confronted with sharp language or threatened by colleagues. Given such behaviours, victims of incivility are trapped in negative psychological states, including severe distress, anxiety and other emotions. ${ }^{38}$ Workplace incivility adversely affects the attitudes and cognitions of new nurses, and drastically decreases their self-confidence. Therefore, they have difficulty objectively evaluating their own work ability, which might be weakened by negative cognitions. Workplace incivility adversely affects new nurses' behaviours, and is more likely to generate negative experiences and behaviours. Negative experiences (eg, role stress) can increase role ambiguity and difficulty adjusting to new roles. This is harmful to the development of their work ability. ${ }^{39}$ Weakened work ability could lead to a lower quality of nursing care. The accumulation of adverse events caused by workplace incivility induces negative emotions, thereby decreasing the organisational commitment of new nurses, ${ }^{40}$ and disrupting their career development. This negative impact is likely to be a long vicious cycle, undermining nursing service quality. A harmonious medical work environment can improve the efficiency and quality of nursing care, and nurses may show altruism and positive behaviour. Clearly, it is a compelling obligation for their colleagues and supervisors to build an environment to provide humanistic care for their development.

Individuals tend to control their own ideas and reactions to achieve their goals. ${ }^{41}$ New nurses who have experienced workplace incivility report greater job-related stress, distraction and dissatisfaction. They experience less creativity and greater psychological distress, which is referred to as 'negative ego'. The low level of motivation leaves the nurses with low expectations in a 'negative ego' state after experiencing workplace incivility. ${ }^{42}$ Their career plans become unclear; thus, they lack internal motivation to achieve higher goals. The ability to defend against external negative incidents is a characteristic of individuals with low expectations. ${ }^{43}$ This leads to role ambiguity, and in turn, reduces work efficiency and the quality of nursing service, thereby impairing overall work performance. However, classical motivational theory shows that high professional expectations raise employees' motivational levels and enhances their performance. ${ }^{44}$ New nurses are full of expectations for professional development and exhibit risk-averse reactions. They are not overly sensitive to negative emotional experiences caused by workplace incivility, ${ }^{45}$ and are focused on how to achieve their desires and ambitions. They are more likely to pursue career success and concentrate on the development of their career; new nurses with high career expectations are more socially involved persistent. They control and adjust their negative emotions to mitigate their inferior status in a timely and effective manner. They are enthusiastic about work and desire to learn nursing skills and function efficiently. These characteristics contributed to their ability to acquire key competencies and assume nursing responsibilities faster and smoother, thereby enhancing 
overall organisational performance. Ultimately, it is realistic for them to achieve a high quality of life and promote the satisfaction of the patients.

\section{Limitations}

Despite the significant findings reported, this study has several limitations. First, the use of a convenience sample increased the risk for sampling bias. Second, the cross-sectional design does not permit making causal inferences about the relationships between the workplace incivility, work ability and job performance. Thus, longitudinal designs are needed in future studies. Third, the use of self-report instruments can result in response bias (social desirability or negative affect). New nurses might have overestimated or underestimated the association between the study variables. Fourth, the samples from the different regions were not proportional, thereby requiring further studies with representative samples. The validity and sensitivity of the single-item questionnaire about career expectations needs further examination. In conclusion, this study focused on workplace incivility and, for the first time, evaluated the current situation in a sample of new nurses working in hospitals in China. The study showed that work ability mediated the relationship between workplace incivility and job performance, and that career expectations moderated the relationship between workplace incivility and job performance. Workplace incivility towards the new nurses impaired their work ability, which was probably followed by a gradual decline in their job performance. In this study, incivility induced 'negative ego', a term we use to describe a state of reduced creativity and greater psychological distress. High career expectations buffered the negative emotional experience of workplace incivility and improved job performance by altering the direction of the relationships. The model generated in this study theoretically extends the research on workplace incivility, especially among new Chinese nurses. It is important for new nurses to adapt to the workplace environment and improve their work ability to promote a high quality of nursing service.

\section{CONCLUSIONS}

This study focused on nursing workplace incivility and, for the first time, evaluates the current situation among China's new nurses. It demonstrates that 'work ability' may serve as an action mechanism that influences the relationship between workplace incivility and job performance. Meanwhile, this relationship may be moderated by career expectation. First, this study examined the association between workplace incivility and job performance of the new nurses in China's nursing workplace. Second, the findings indicate that work ability mediated the association between workplace incivility and job performance of the new nurses. Third, it demonstrates that career expectation moderated the relationship between workplace incivility and job performance. Namely, Workplace incivility in hospitals towards new nurses could weaken their work ability and, in turn, gradually reduced job performance. In this process, incivility induced negative ego. A high level of career expectation could buffer negative emotional experience caused by nursing workplace incivility and improve performance by adjusting the directional motives. The model theoretically extends the study of workplace incivility, especially to the Chinese new nursing group. It is significant for new nurses to adapt to the environment and improve work ability for the purpose of promoting nursing service quality.

\section{Author affiliations}

${ }^{1}$ Department of Health Management, School of Public Health, Harbin Medical University, Harbin, China

${ }^{2}$ Department of Cardiac Surgery, Second Affiliated Hospital of Harbin Medical University, Harbin, China

${ }^{3}$ Department of Administration, Second Affiliated Hospital of Harbin Medical University, Harbin, China

${ }^{4}$ Department of Outpatient Operating Room, First Affiliated Hospital of Harbin Medical University, Harbin, China

${ }^{5}$ Department of Internal Medicine, Harbin Medical University Cancer Hospital, Harbin, China

${ }^{6}$ Department of Medical Examination Center, The Second Affiliated Hospital of Harbin Medical University, Harbin, China

Acknowledgements The authors would like to thank all the participants who helped us collect data and distribute questionnaires to the other subjects.

Contributors Conceived and designed the experiments: TS, SZ, CM. Conducted the survey: SZ, CM, YS, FX, JL, SC, XD. Analysed the data: TS, SZ. Contributed reagents/ materials/analysis tools: DM, JW, CM. Wroten the paper: SZ, CM, TS.

Funding This study was funded by the Innovation Science Research Foundation Project of Harbin Medical University (No. 2016RWZX09) led by TS.

\section{Competing interests None declared.}

Patient consent Obtained.

Ethics approval This study was approved by the institutional review board of Harbin Medical University.

Provenance and peer review Not commissioned; externally peer reviewed.

Data sharing statement № additional data are available.

Open access This is an open access article distributed in accordance with the Creative Commons Attribution Non Commercial (CC BY-NC 4.0) license, which permits others to distribute, remix, adapt, build upon this work non-commercially, and license their derivative works on different terms, provided the original work is properly cited, appropriate credit is given, any changes made indicated, and the use is non-commercial. See: http://creativecommons.org/licenses/by-nc/4.0/.

\section{REFERENCES}

1. Andersson LM, Pearson CM. Tit for tat? the spiraling effect of incivility in the workplace. Acad Manage Rev 1999;24:452-71.

2. Schilpzand P, De Pater IE, Erez A. Workplace incivility: A review of the literature and agenda for future research. J Organ Behav 2016;37(4):S57-S88.

3. Liu C. A literature review on workplace incivility. Chinese Journal of Management 2012;9:1092-8.

4. Bambi S, Guazzini A, De Felippis C, et al. Preventing workplace incivility, lateral violence and bullying between nurses $A$ narrative literature review. Acta Biomed 2017;88:39.

5. Oyeleye O, Hanson P, O'Connor N, et al. Relationship of workplace incivility, stress, and burnout on nurses' turnover intentions and psychological empowerment. J Nurs Adm 2013;43:536-42.

6. Yu M, Kang KJ. Factors affecting turnover intention for new graduate nurses in three transition periods for job and work environment satisfaction. J Contin Educ Nurs 2016;47:120-31.

7. Lim S, Cortina LM, Magley VJ. Personal and workgroup incivility: impact on work and health outcomes. J Appl Psychol 2008;93:95-107.

8. Spiri C, Brantley M, McGuire J. Incivility in the workplace: a study of nursing staff in the military health system. $J$ Nurs Educ Pract 2016;7:40-6. 
9. Liu CE. The study on evolution mode and countermeasures of workplace incivility. East China Economic Management 2012;26:129-32.

10. MacWilliams BR, Schmidt B, Bleich MR. Men in nursing. AJN, American Journal of Nursing 2013;113:38-44.

11. Khadjehturian RE. Stopping the culture of workplace incivility in nursing. Clin J Oncol Nurs 2012;16:638-9.

12. Hodgins M, MacCurtain S, Mannix-McNamara P. Workplace bullying and incivility: a systematic review of interventions. Int $J$ Workplace Health Manag 2014;7:54-72.

13. Chen SH, Chen MF, Kuo ML, et al. Predictor of self-perceived nursing competency among new nurses in Taiwan. J Contin Educ Nurs 2017;48:129-37.

14. Missen K, McKenna L, Beauchamp A, et al. Qualified nurses' rate new nursing graduates as lacking skills in key clinical areas. J Clin Nurs 2016;25:2134-43.

15. Reich TC, Hershcovis MS. Observing workplace incivility. J Appl Psychol 2015;100:203-15.

16. Wing T, Regan S, Spence Laschinger HK. The influence of empowerment and incivility on the mental health of new graduate nurses. J Nurs Manag 2015;23:632-43.

17. Laschinger HK, Wong C, Regan S, et al. Workplace incivility and new graduate nurses' mental health: the protective role of resiliency. $J$ Nurs Adm 2013;43:415-21.

18. Asim Faheem M, Mahmud N. Workplace incivility in predicting turnover intentions and job performance: study on nurses of public sector hospitals of Pakistan. Research Journal of Applied Sciences, Engineering and Technology 2015;10:863-70.

19. Rahim A, Cosby DM. A model of workplace incivility, job burnout, turnover intentions, and job performance. Journal of Management Development 2016;35:1255-65.

20. Chang YQ. Investigation analysis on work adaptation and humanistic care of new nurses and its countermeasures. Nursing Practice \& Research 2017;14:87-9.

21. Boschman JS, Nieuwenhuijsen K, Frings-Dresen MH, et al. Development of hospital nurses' work ability over a 2 year period. Occup Med 2015;65:542-8.

22. Bang SS, Kim I-O, et al. Relationship among essentials of fundamental nursing skills performance, stress from work and work capability of new clinical nurses. The Journal of Korean Academic Society of Nursing Education 2014;20:628-38.

23. Bernburg M, Vitzthum K, Groneberg DA, et al. Physicians' occupational stress, depressive symptoms and work ability in relation to their working environment: a cross-sectional study of differences among medical residents with various specialties working in German hospitals. BMJ Open 2016;6:e011369.

24. Moon B, Harris B. Career motivations, role expectations and curriculum knowledge of prospective secondary english teachers in Western Australia. Australian Journal of Teacher Education 2016;41:41-66.

25. Qi Y, Hua-Wei MA, Yue GA, et al. Success expectations and performance: regulatory focus as a moderator: success expectations and performance: regulatory focus as a moderato. Acta Psychologica Sinica 2010;42:704-14.

26. Rhee SY, Hur WM, Kim M. The relationship of coworker incivility to job performance and the moderating role of self-efficacy and compassion at work: The Job Demands-Resources (JD-R) Approach. Journal of Business \& Psychology 2016;32:1-16.

27. Cortina LM, Kabat-Farr D, Leskinen EA, et al. Selective incivility as modern discrimination in organizations. J Manage 2013;39:1579-605.
28. Meng DX, Shi Y, Xie FZ, et al. Measures and its influence on turnover intention of uncivilized behaviors by new nurses at workplace. Chinese Hospital Management 2017;37:62-4.

29. Ahlstrom L, Grimby-Ekman A, Hagberg M, et al. The work ability index and single-item question: associations with sick leave, symptoms, and health - a prospective study of women on long-term sick leave. Scand J Work Environ Health 2010;36:404-12.

30. Wanous JP, Reichers AE, Hudy MJ. Overall job satisfaction: how good are single-item measures? J Appl Psychol 1997;82:247-52.

31. Williams LJ, Anderson SE. Job satisfaction and organizational commitment as predictors of organizational citizenship and in-role behaviors. J Manage 1991;17:601-17.

32. Baron RM, Kenny DA. The moderator-mediator variable distinction in social psychological research: conceptual, strategic, and statistical considerations. J Pers Soc Psychol 1986;51:1173-82.

33. Gallus JA, Bunk JA, Matthews RA, et al. An eye for an eye? Exploring the relationship between workplace incivility experiences and perpetration. J Occup Health Psychol 2014;19:143-54.

34. Yan X, Su J, Wen Z, et al. The role of work engagement on the relationship between personality and job satisfaction in chinese nurses. Curr Psychol 2017;28:1-6.

35. Kabat-Farr D, Walsh BM, McGonagle AK. Uncivil supervisors and perceived work ability: the joint moderating roles of job involvement and grit. Journal of Business Ethics 2017;36:1-15.

36. Weiss HM, Cropanzano R. Affective Events Theory: A theoretical discussion of the structure, causes and consequences of affective experiences at work. Research in Organizational Behavior 1996;18:1-74.

37. Olsen E, Bjaalid G, Mikkelsen A. Work climate and the mediating role of workplace bullying related to job performance, job satisfaction, and work ability: A study among hospital nurses. J Adv Nurs 2017;73:2709-19.

38. Itzkovich $\mathrm{Y}$. The victim perspective of incivility: the role of negative affectivity, hierarchical status and their interaction in explaining victimisation. International Journal of Work Organisation and Emotion 2016;7:126-42.

39. Liu Y, Yang M, Chen FF. Impact of young ICU nurses' role conflict,role ambiguity and job burnout on their turnover intention in ICU department. Chinese Journal of Nursing 2013;48:533-5.

40. Kim SY, Kim JK, Park K-O. Path analysis for workplace incivility, empowerment, burnout, and organizational commitment of hospital nurses. Journal of Korean Academy of Nursing Administration 2013;19:555-64.

41. Higgins T, Tykocinski O. Seff-discrepancies and biographical memory: personality and cognition at the level of psychological situation. Personality and Social Psychology Bulletin 1992;18:527-35.

42. Liberman N, Idson LC, Higgins ET. Predicting the intensity of losses vs. non-gains and non-losses vs. gains in judging fairness and value: A test of the loss aversion explanation. J Exp Soc Psychol 2005;41:527-34

43. Muldoon OT, Kremer JM. Career aspirations, job satisfaction and gender identity in female student nurses. J Adv Nurs 1995;21:544-50.

44. Gkioka V, Petrakos A, Sarris M, et al. Motivation factors of doctors and nurses in the health services. Archives of Hellenic Medicine 2018;35:230-40.

45. Porath CL, Pearson CM. Emotional and behavioral responses to workplace incivility and the impact of hierarchical status. J App/ Soc Psychol 2012;42:E326-E357. 